\title{
Modeling of intermolecular interactions between epoxyamine grid and hydroxide of metals
}

\author{
$\underline{\text { Yuliya Danchenko }}{ }^{1}$, Elena Barabash ${ }^{1}$, Alexandra Strumskas ${ }^{2}$ \\ 1. Department of General Chemistry, Kharkiv National University of Civil Engineering and Architecture, \\ UKRAINE, Kharkiv, 40, Sumska Street, E-mail: u_danchenko@ukr.net \\ 2. Department of General Chemistry, Kharkiv National University of Civil Engineering and Architecture, \\ UKRAINE, Kharkiv, 40, Sumska Street, E-mail: elenlol90@gmail.com \\ 3. Architectural faculty, Kharkiv National University of Civil Engineering and Architecture, \\ UKRAINE, Kharkiv, 40, Sumska Street, E-mail: $\underline{\text { sandrysik13@ @rambler.ru }}$
}

\begin{abstract}
The method of quantum-chemical modeling investigates intermolecular interactions between epoxyamine grid and hydroxides of metals of various chemical nature. It was established that the influence of hydroxide on the structure and spatial conformation of the grid depends on the acid-base properties and increases with increasing alkalinity of the hydroxide. It is shown that for certain an alkaline property of hydroxide, due to strong intermolecular interactions, the spatial conformation of the grid is significantly changed.
\end{abstract}

Key words - epoxyamine grid, metal hydroxide, intermolecular interactions, acid-base properties

\section{Introduction}

Disperse oxides and metal hydroxides are successfully used as fillers to produce composite materials based on epoxyamine polymers. The properties of filled epoxy materials depend to a large extent on intermolecular interactions on the phase separation surface. It is known that on the surface of disperse-dry fillers due to adsorption of water molecules a hydroxyl-hydrated layer is formed, represented by hydroxyl groups with different acidity. Surface hydroxyl groups interact with epoxy polymer, which significantly affects the technological, physic-chemical, protective and other properties of composite materials. Therefore, the study of the patterns of intermolecular interactions between the epoxy grid and metal hydroxides is necessary in terms of directional regulation and prediction of the properties of composite polymeric materials.

\section{Results of simulation of molecular complexes}

To simulate the interactions between epoxyamine grid polymer and hydroxides of metals of different chemical nature, a fragment of a grid formed as a result of the crosslinking of two molecules of the epoxydian oligomer brand ED-20 and one of the molecule of the diethylenetriamine brand DETA has been used. The investigated molecular complexes consisted of a grid fragment $(\mathrm{EP})$ and a metal hydroxide metals $\mathrm{Al}(\mathrm{OH})_{3}, \mathrm{Fe}(\mathrm{OH})_{3}, \mathrm{Ti}(\mathrm{OH})_{4}, \mathrm{Ca}(\mathrm{OH})_{2}$. In fig. 1 shows three-dimensional models of a fragment of epoxyamin grid and molecular complexes constructed with the help of the HyperChem software package with geometric optimization function.

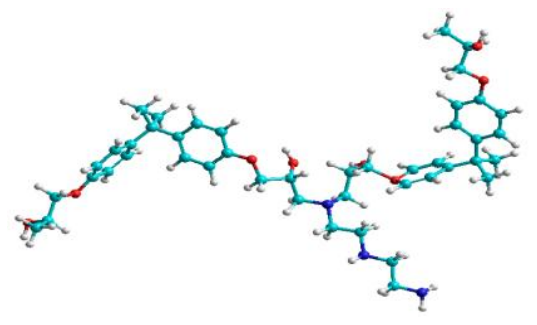

a

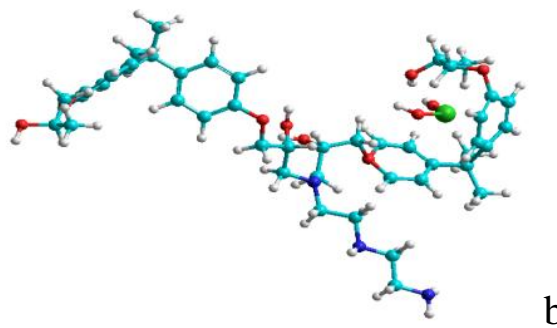

Fig. 13 -D models of: $a$ - fragment of epoxyamine grid EP, $b$ - molecular complex $\mathrm{EP}+\mathrm{Ca}(\mathrm{OH})_{2}$, with conditional designations of atoms $-\mathrm{C} ;-\mathrm{O} ;-\mathrm{H} ;-\mathrm{N} ;-\mathrm{Ca}$. 
As a result of modeling, we obtained the values of intermolecular distance and dipole moments $(\mu)$ of molecules and molecular complexes, enthalpy formation $\left(\Delta H_{\text {form }}\right)$ and energy of interaction $\left(E_{\text {int }}\right)$ of molecules in the complexes.

Calculation results are shown in Table 1.

Table 1

Energy and dimensional parameters of molecules and molecular complexes

\begin{tabular}{|c|c|c|c|c|}
\hline Complex & $\begin{array}{c}\Delta \mathrm{H}_{\text {form }}, \\
\mathrm{kJ} / \mathrm{mol}\end{array}$ & $\mathrm{E}_{\mathrm{int}}, \mathrm{kJ} / \mathrm{mol}$ & $\begin{array}{c}\text { Distance between } \\
\text { molecules, } \AA\end{array}$ & $\begin{array}{c}\text { Dipole moment, } \\
\mu, \mathrm{D}\end{array}$ \\
\hline Fragment of grid (EP) & $-1,522.4$ & - & - & 6.15 \\
\hline $\mathrm{Ti}(\mathrm{OH})_{4}$ & $-1,170.7$ & - & - & 0.15 \\
\hline $\mathrm{EP}+\mathrm{Ti}(\mathrm{OH})_{4}$ & $-1,931.8$ & 181.9 & 5.9 & 6.20 \\
\hline $\mathrm{Ca}(\mathrm{OH})_{2}$ & -872.3 & - & - & 0.07 \\
\hline $\mathrm{EP}+\mathrm{Ca}(\mathrm{OH})_{2}$ & $-3,603.6$ & -288.7 & $1.7-2.5$ & 4.50 \\
\hline $\mathrm{Al}(\mathrm{OH})_{3}$ & -949.1 & - & - & 2.37 \\
\hline $\mathrm{EP}+\mathrm{Al}(\mathrm{OH})_{3}$ & $-1,710.1$ & 181.9 & 5.6 & 8.14 \\
\hline $\mathrm{Fe}(\mathrm{OH})_{3}$ & $-1,515.0$ & - & - & 3.18 \\
\hline $\mathrm{EP}+\mathrm{Fe}(\mathrm{OH})_{3}$ & $-2,276.3$ & 181.8 & $3.2-3.9$ & 9.08 \\
\hline
\end{tabular}

As a result of quantum-chemical modeling with the use of HyperChem software package, the following energy and dimensional parameters of molecules and molecular complexes were obtained. Selected systems give an idea of possible intermolecular interactions and formation of non-covalent bonds on the surface of separation of phases in epoxyamine polymer composites [1].

As Fig. $1 a$ of the model shows, a fragment of the epoxyamine grid is rather nonsymmetrical and has a spatial configuration of a high dipole moment $\mu=6.15 \mathrm{D}$. The rest of the molecule of diethylegridriamine is located between residues of ED-20 molecules that repel. Obviously, the residues of ED-20 molecules, which contain benzene rings with delocalized $\pi$ bond, repel from nitrogen atoms of DETA residue. By comparing resulting energy and dimensional parameters of the molecular complexes between EP and hydroxides of metals of different chemical nature, it is necessary to note significant influence of the nature of metal (Table 1). Molecular complexes with dipole moment, which is more than $\mu$ of individual molecules, are formed at interaction in most cases. Thus, dipole moment of complex $\mathrm{EP}+\mathrm{Fe}(\mathrm{OH})_{3}(\mu=9.08 \mathrm{D})$ is 1.5 times as high as dipole moment of $\mathrm{EP}(\mu=6.15 \mathrm{D})$ and 3 times as high as dipole moment of $\mathrm{Fe}(\mathrm{OH})_{2}(\mu=3.18 \mathrm{D})$. Dipole moments of complexes $\mathrm{EP}+\mathrm{Ti}(\mathrm{OH})_{4}$ and $\mathrm{EP}+\mathrm{Al}(\mathrm{OH})_{3}$ exceed $\mu$ of source molecules as well. In the case of $\mathrm{EP}+\mathrm{Ca}(\mathrm{OH})_{2}$, on the contrary, dipole moment of the complex $(\mu=4.50 \mathrm{D})$ is by 1.4 times less than dipole moment of EP, but by 2 orders of magnitude larger than $\mu$ of $\mathrm{Ca}(\mathrm{OH})_{2}$. Obviously, it is connected with the fact that compared with metals of amphoteric nature ( $\mathrm{Ti}, \mathrm{Fe}, \mathrm{Al}), \mathrm{Ca}$ is strong alkaline-earth. It is characteristic that in this complex the distance between molecules is the least $(1.7-2.5 \AA)$, and interactions are the strongest $\left(\mathrm{E}_{\mathrm{int}}=-288.7 \mathrm{~kJ} / \mathrm{mol}\right)$. This is due to the fact that a molecule of $\mathrm{Ca}(\mathrm{OH})_{2}$ interacts with EP by a fundamentally different mechanism from hydroxides $\mathrm{Ti}(\mathrm{OH})_{4}$, $\mathrm{Al}(\mathrm{OH})_{3}$ and $\mathrm{Fe}(\mathrm{OH})_{3}$. Thus, Fig. $1 b$ shows that existence of a $\mathrm{Ca}(\mathrm{OH})_{2}$ molecule causes a change in special conformation of the grid's fragment. Calcium atom is oriented to $\pi$-electron cloud of benzene ring with formation of donor-acceptor bond. At the same time, OH-groups of calcium hydroxide form hydrogen bonds with OH-groups of the residue of a ED-20 molecule. 
This conclusion follows from the values of the measured distance between a $\mathrm{Ca}(\mathrm{OH})_{2}$ molecule and EP, which are compared to the length of hydrogen bond, equal to about $3 \AA$ A. In general, it should be noted that calcium hydroxide has the greatest influence on spatial conformation of epoxyamine fragment and causes substantial changes in all energy and dimensional parameters of the grid. As a result of geometric optimization of molecular complexes, it was established that hydroxides $\mathrm{Ti}(\mathrm{OH})_{4}, \mathrm{Al}(\mathrm{OH})_{3}$ and $\mathrm{Fe}(\mathrm{OH})_{3}$ are oriented by hydroxyl groups to $\mathrm{OH}$-groups of the grid's fragment. They are located on the opposite side from the residue of a diethanolamine molecule. Location like this is, obviously, the most energy- and spatially conditioned by conformation. The values of enthalpies of formation of the studied molecules and molecular complexes are negative (Table 1). Absolute values of $\Delta \mathrm{H}_{\text {form }}$ complexes are by 1.5-4 times higher than $\Delta \mathrm{H}_{\text {form }}$ of separate molecules. In other words, intermolecular interactions between the studied molecules are energetically predefined. At the same time, obtained results of modeling make it possible to argue that interactions between the hydroxides of amphoteric metals and epoxyamine grid are weak and low-energy. The distances between EP and metal hydroxides are small (3.2-5.9 $\AA$ ) and are comparable with the distance, which are characteristic for formation of a hydrogen bond (about $3 \AA \AA$ ). Energy of interaction of hydroxides $\mathrm{Ti}(\mathrm{OH})_{4}$, $\mathrm{Al}(\mathrm{OH})_{3}$ i $\mathrm{Fe}(\mathrm{OH})_{3}$ and $\mathrm{EP}$ grid fragment have close values at different distances between molecules in complexes. Small values of energies of interaction at sufficiently high values of dipole moments $(\mu=6.20-9.08 \mathrm{D}$ ) indicate formation of low-energy inductive and, possibly, dipole-dipole (orientationally) intermolecular interactions. The obtained data show that existence of amphoteric hydroxides does not cause a change in spatial conformation of the EP fragment. From results of quantum-chemical modeling, it follows that ability of metal hydroxides affect the conformation of a fragment of the epoxyamine grid increases in the series: $\mathrm{Ti}(\mathrm{OH})_{3}<\mathrm{Al}(\mathrm{OH})_{3}<\mathrm{Fe}(\mathrm{OH})_{3}<\mathrm{Ca}(\mathrm{OH})_{2}$. This series coincides with the series, in which basic properties increase (acidic properties weaken) of the active Branstad centers (OH-groups) with the central elements: $\mathrm{Ti}^{4+}<\mathrm{Al}^{3+}<\mathrm{Fe}^{3+}<\mathrm{Ca}^{2+}[2]$.

\section{Conclusion}

Thus, as a result of quantum-chemical modeling, it was found that the influence of the hydroxide of metal on the structure and spatial conformation of epoxyamine grid depends on the acidic-basic properties and increases at an increase of basic (alkaline) properties of an hydroxide due to strong intermolecular interactions (formation of hydrogen and donor-acceptor bonds), the spatial conformation of epoxyamine grid changes significantly. It was shown that between $\mathrm{OH}-$ groups of hydroxides of amphoteric nature and the epoxyamine grid, weak low-energy bonds of orientation and induction character are formed. In this case, spatial conformation of the grid's fragment does not change. In general, we can conclude that the nature and energy of intermolecular bonds, which affect the structure of epoxyamine polymer composites, are determined by acidic-basic properties and the chemical nature of the hydroxide of metal.

\section{References}

[1] Yu. Danchenko, V. Andronov, E. Barabash, T. Obigenko, E. Rybka, R. Meleshchenko, and A. Romin, "Research of the intermolecular interactions and structure in epoxyamine composites with dispersed oxides", Eastern-European Journal of Enterprise Technologies, vol. 6, no. 12(90), pp. 4-12, 2017.

[2] Yu. Danchenko, V. Andronov, E. Rybka, and S. Skliarov, "Investigation into acid-basic equilibrium on the surface of oxides with various chemical nature", Eastern-European Journal of Enterprise Technologies, vol. 4, no. 12(88), pp. 17-25, 2017.

$2^{\text {nd }}$ INTERNATIONAL SCIENTIFIC CONFERENCE “CHEMICAL TECHNOLOGY AND ENGINEERING - 2”, JUNE 24-28 ${ }^{\text {TH }}, 2019$, LVIV, UKRAINE 